\title{
Enantioselective and Regioselective Copper-Catalyzed Borocyanation of 1-Aryl-1,3-Butadienes
}

DOI:

10.1021/acscatal.9b01911

\section{Document Version}

Accepted author manuscript

Link to publication record in Manchester Research Explorer

\section{Citation for published version (APA):}

Jia, T., Smith, M. J., Pulis, A. P., Perry, G. J. P., \& Procter, D. J. (2019). Enantioselective and Regioselective Copper-Catalyzed Borocyanation of 1-Aryl-1,3-Butadienes. ACS Catalysis, 6744-6750.

https://doi.org/10.1021/acscatal.9b01911

\section{Published in:}

ACS Catalysis

\section{Citing this paper}

Please note that where the full-text provided on Manchester Research Explorer is the Author Accepted Manuscript or Proof version this may differ from the final Published version. If citing, it is advised that you check and use the publisher's definitive version.

\section{General rights}

Copyright and moral rights for the publications made accessible in the Research Explorer are retained by the authors and/or other copyright owners and it is a condition of accessing publications that users recognise and abide by the legal requirements associated with these rights.

\section{Takedown policy}

If you believe that this document breaches copyright please refer to the University of Manchester's Takedown Procedures [http://man.ac.uk/04Y6Bo] or contact uml.scholarlycommunications@manchester.ac.uk providing relevant details, so we can investigate your claim.

\section{OPEN ACCESS}




\title{
Enantioselective and Regioselective Copper-Catalyzed Borocya- nation of 1-Aryl-1,3-Butadienes
}

\author{
Tao Jia, ${ }^{\dagger, \star}$ Marshall J. Smith, ${ }^{\dagger}$ Alexander P. Pulis, ${ }^{\dagger}$ Gregory J. P. Perry ${ }^{\dagger}$ and David, J. Procter ${ }^{\dagger}{ }^{\dagger}$ \\ ${ }^{\dagger}$ School of Chemistry, University of Manchester, Oxford Rd, Manchester, M13 9PL (UK) \\ ${ }^{\ddagger}$ College of Chemistry and Materials Science, Sichuan Normal University, Chengdu, 610068 (P. R. China)
}

\begin{abstract}
A multicomponent copper-catalyzed enantio- and regioselective borocyanation of 1-aryl-1,3-butadienes has been developed. The method provides access to functionalized allylic nitriles in up to $90 \%$ yield and $94 \%$ ee and thus overcomes some of the long-standing problems associated with the enantioselective insertion of cyano groups into unsaturated organic molecules. Both boron and cyano functionalities can be used as handles for selective manipulation.
\end{abstract}

\section{KEYWORDS: copper, 1,3-dienes, borylation, asymmetric catalysis, cyanation}

Incorporating cyano groups into unsaturated hydrocarbons using transition metal catalysis is established as a highly vital process. ${ }^{1}$ The importance of such procedures is best illustrated by the industrial production of adiponitrile, ${ }^{2}$ a key precursor to nylon- 6,6 , that is currently produced on a $>2$ million metric ton scale each year by a nickel-catalyzed hydrocyanation of butadiene (the most simple 1,3-diene). ${ }^{3}$ Intense investigation into this reaction has contributed to some of the fundamental principles of organometallic chemistry. ${ }^{4}$ It is clear that the cyanation of 1,3-dienes is an attractive route for the construction of useful molecules, however, the application of this methodology in complex organic synthesis has stalled due to a lack of enantioselective methods. ${ }^{5}$

Synthetic strategies involving the addition of copper hydride $(\mathrm{Cu}-\mathrm{H})$ or copper-boryl $(\mathrm{Cu}-\mathrm{B})$ complexes across $\mathrm{C}=\mathrm{C}$ double bonds, followed by reaction of the resultant organocopper species with electrophiles, have seen great development in recent years. ${ }^{6,7}$ In particular, the copper-catalyzed borofunctionalization of dienes is an attractive route for the rapid buildup of molecular complexity from simple reagents using an inexpensive, non-toxic catalyst. ${ }^{8,9}$ However, there are challenges associated with the borofunctionalization of dienes (Scheme 1); for example, ensuring the $\mathrm{Cu}-\mathrm{B}$ species (I) reacts with a particular substrate (chemoselectivity, $i)^{10}$ and in a specific fashion (regioselectivity, ii). Furthermore, if borofunctionalization is to show its full synthetic utility the development of enantioselective processes are necessary (Scheme 1, step iii).

Scheme 1. The challenges in $\mathrm{Cu}$-catalyzed borofunctionalizations of dienes: chemo-, regio- and enantioselectivity.

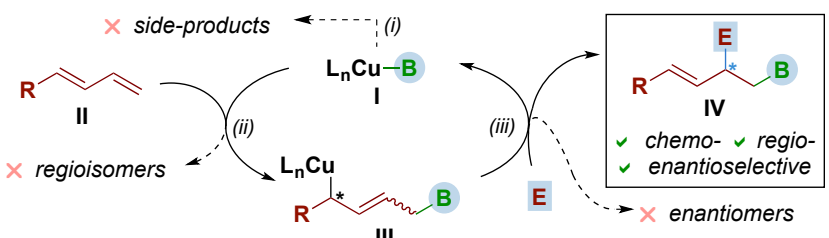

B = boron functionality (e.g. BPin)

E = electrophile (e.g. carbonyl, iminyl)
Scheme 2. A. Rare examples of the enantioselective coppercatalyzed borofunctionalization of dienes. B. Proposed enantioselective copper-catalyzed borocyanation of dienes

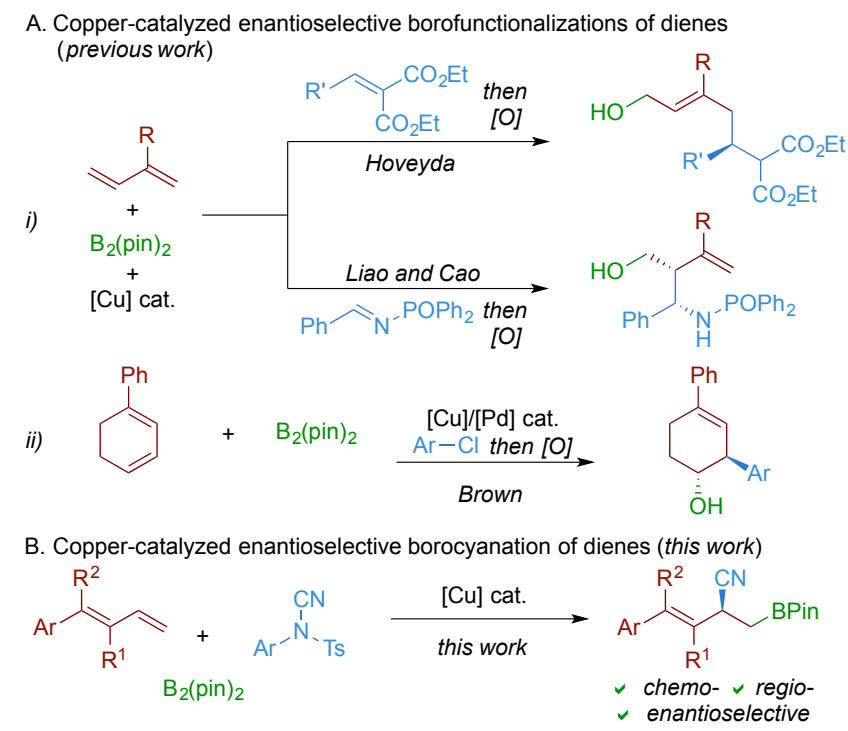

Despite these challenges, the first examples of 1,3-diene borofunctionalization have surfaced over the past few years. In 2016, the groups of Hoveyda, ${ }^{11}$ and Liao and $\mathrm{Cao}^{12}$ reported the enantioselective carboboration of butadiene, isoprene and other 1,3-dienes (Scheme 2A, i). In these cases, the in situ generated allyl-Cu species ( $c f$ Scheme 1, III) were trapped with a carbon electrophile (either an enoate or an imine). More recently, Brown and co-workers have developed a similar methodology that uses isoquinolines as imine equivalents, ${ }^{13}$ and have also revealed an approach to the enantioselective arylboration of cyclic arylbutadienes (Scheme $2 \mathrm{~A}, \boldsymbol{i i}){ }^{14}$ Their procedure merges two catalytic cycles: a copper cycle for incorporating boron functionality and a palladium cycle to promote arylation. These three reports demonstrate the current state-of-the-art in enantioselective borofunctionalizations of dienes and go some way to revealing the potential of coppercatalyzed multifunctionalizations. 
Continuing our work on copper catalyzed functionalizations of unsaturated hydrocarbons, we were keen to develop an enantioselective method for the borocyanation of 1,3-dienes (Scheme 2B). ${ }^{8 c, 15}$ If successful, this procedure would yield enantioenriched products bearing both cyano and boron groups, which are ideal for further functionalization. Progress has been made in the field of copper-catalyzed borocyanation, ${ }^{7}$ including recent reports by ourselves ${ }^{8 \mathrm{c}}$ and Meng et $a l^{8 \mathrm{~d}}$ on the borocyanation of 1,3-dienes. However, methods for the enantioselective borocyanation of dienes have not been reported. ${ }^{16}$ We believe that the procedure described herein not only represents an interesting example of copper-catalyzed borofunctionalization, but also provides a significant advance in the wider area of enantioselective cyanation of unsaturated hydrocarbons.

We began our investigation by attempting the coppercatalyzed borocyanation of 1-phenyl-1,3-butadiene 1a with $\mathrm{B}_{2}$ (pin) $)_{2} 2$ and the cyanating agent $\mathbf{3}$ (Table 1). ${ }^{17,18}$ Our previous studies revealed that phosphine ligands can promote regioselective borocyanation. ${ }^{8 c}$ Therefore, $(R)$-BINAP L1 was initially tested (Table 1, Entry 1). This provided a good overall yield of product, however, the regioselectivity of the reaction was poor giving a roughly 50:50 mixture of regioisomers 4 a and 5a. Despite this, the enantioselectivity of the procedure (45\% ee for $4 \mathbf{a})$ was encouraging. A similar $\mathrm{C}_{2}$-symmetric bidentate phosphine, $(R)$-SEGPHOS L2, was also tested, but provided similar yields, regioselectivity and enantioselectivity (Table 1, entry 2). During the 1990's, the groups of Williams, Pfaltz and Helmchen developed a class of non-symmetric chiral phosphinooxazoline (PHOX) ligands. ${ }^{19}$ These ligands were found to give superior enantioselectivities and regioselectivities in palladium-catalyzed allylic substitution reactions that proceed via $\mathrm{L}_{\mathrm{n}} \mathrm{Pd}$-allyl intermediates. We questioned whether PHOX ligands would also prove useful in borocyanations proceeding via $\mathrm{L}_{\mathrm{n}} \mathrm{Cu}$-allyl intermediates. Interestingly, PHOX ligands have been little used in copper-catalyzed borofunctionalizations of unsaturated bonds. ${ }^{20}$ Our initial result indeed revealed that PHOX ligand $\mathbf{L 3}$ could impart complete regioselectivity, however, this came at the detriment of enantioselectivity ( $6 \%$ ee, Table 1, Entry 3$)$. This demonstrated the challenge of controlling both the regioselectivity and the enantioselectivity of borofunctionalization processes. We then replaced the pendent group at the stereogenic center of the oxazoline ring and found that the ligand substituted with a bulky ${ }^{\mathrm{t}} \mathrm{Bu}$ group, $\mathbf{L 5}$, provided a significant increase in enantioselectivity (54\% ee, Table 1, Entry 5). Likewise, changing the aryl substituents on the phosphorus atom also allowed us to tune the regio- and enantioselectivity of the reaction (Table 1 Entries 6, 7). Ultimately, ligand $\mathbf{L} 7$, which features aryl substituents bearing electron-withdrawing groups, was revealed to be the ligand of choice in this process (Table 1, Entry 7). By changing the copper source to $\mathrm{CuTc}$ (copper(I) thiophene-2carboxylate) and the solvent to $\mathrm{Et}_{2} \mathrm{O}$ a significant increase in yield and enantioselectivity was observed (Table 1, Entry 9). Finally, by lowering the temperature to $0{ }^{\circ} \mathrm{C}$ and inverting the equivalents of diene 1 to cyanating agent 3 , the product could be isolated in a high yield of $83 \%$ as a single regioisomer and with excellent enantioselectivity ( $91 \%$ ee, Table 1, Entry 12$).{ }^{21}$ The reaction was also performed on a $5 \mathrm{mmol}$ scale using reduced loadings ( $5 \mathrm{~mol} \%$ ) of catalyst and ligand to show the potential of this procedure for large scale production (Table 1 entry 15). Additional experiments revealed that $\mathrm{K}_{3} \mathrm{PO}_{4}$ was also a suitable base for this transformation (Table 1, entry 13).
Interestingly, butoxide salts, which are usually the base of choice in similar borofunctionalizations, provided the product with only moderate enantioselectivity (Table 1 , entry 14). We believe this is due to the strong butoxide base deprotonating the product and leading to racemization. We have therefore developed a unique system for copper catalyzed borofunctionalizations that uses a base strong enough to activate the boron reagent, but mild enough to avoid racemization.

Table 1. Optimisation of the copper-catalyzed regio- and enantioselective borocyanation of 1,3-dienes. ${ }^{a}$

[Cu] cat. (10 mol\%)
Ligand $(10 \mathrm{~mol} \%)$

${ }^{a}$ Reaction conditions: Diene $1(0.2 \mathrm{mmol}), \mathrm{B}_{2} \operatorname{pin}_{2} 2(0.4 \mathrm{mmol})$, cyanating agent $3(0.26 \mathrm{mmol}), \mathrm{Cu}$ cat. $(0.02 \mathrm{mmol})$, Ligand $(0.02$ $\mathrm{mmol}), \mathrm{K}_{2} \mathrm{CO}_{3}(0.24 \mathrm{mmol})$, solvent $(4.0 \mathrm{~mL}), \mathrm{rt}, 16 \mathrm{~h} .{ }^{b}$ Reaction run at $0{ }^{\circ} \mathrm{C}$. ${ }^{c}$ Diene $1(0.4 \mathrm{mmol}), \mathrm{B}_{2} \mathrm{pin}_{2} 2(0.4 \mathrm{mmol})$, cyanating agent $3(0.2 \mathrm{mmol}), \mathrm{Cu}$ cat. $(0.02 \mathrm{mmol})$, Ligand $(0.02 \mathrm{mmol})$, $\mathrm{K}_{2} \mathrm{CO}_{3}(0.24 \mathrm{mmol})$, solvent $(4.0 \mathrm{~mL}), 0{ }^{\circ} \mathrm{C}, 16 \mathrm{~h} .{ }^{d}$ Isolated yield of $4 \mathrm{a} .{ }^{e} \mathrm{~K}_{3} \mathrm{PO}_{4}$ used as base. ${ }^{f} \mathrm{KO}^{t} \mathrm{Bu}$ used as base. ${ }^{g}$ Large scale: diene 1 (10 mmol), $B_{2} \operatorname{pin}_{2} 2$ (10 mmol), cyanating agent 3 (5 $\mathrm{mmol}), \mathrm{Cu}$ cat. $(0.25 \mathrm{mmol})$, Ligand $(0.25 \mathrm{mmol}), \mathrm{K}_{2} \mathrm{CO}_{3}(6$ mmol), solvent $(100 \mathrm{~mL}), 0{ }^{\circ} \mathrm{C}, 16 \mathrm{~h}$.

We then looked to establish the tolerance of the reaction towards substituents on the aryl ring of the butadiene (Scheme $3 \mathrm{~A}){ }^{18}$ The regioselectivity of the reaction remained very high for all cases described herein - at most, the minor regioisomer 5 was only ever observed in trace amounts $(<4 \%)$, unless otherwise stated. Our first observation was that electron-donating substituents lower the yield of the reaction, but that the enantioselectivity of the reaction remains unaffected $(\mathbf{4 b}, \mathbf{4 c})$. The 
lower yield may be due to a less favorable addition of a nucleophilic $\mathrm{L}_{\mathrm{n}} \mathrm{Cu}-\mathrm{Bpin}$ species across the $\mathrm{C}=\mathrm{C}$ bond of a more electron-rich diene. ${ }^{22}$ Applying the optimized conditions to a range of halogen-substituted arylbutadienes, including bromosubstituted diene 1g, gave the corresponding products in high yields and excellent enantioselectivities (4e-4g). Other substrates bearing electron-withdrawing substituents, such as trifluoromethyl- (4h) and ester-groups (4i), were also tested and gave the

\section{Scheme 3. Scope of the copper-catalyzed enantioselective borocyanation of 1-(hetero)arylbutadienes. ${ }^{a}$}
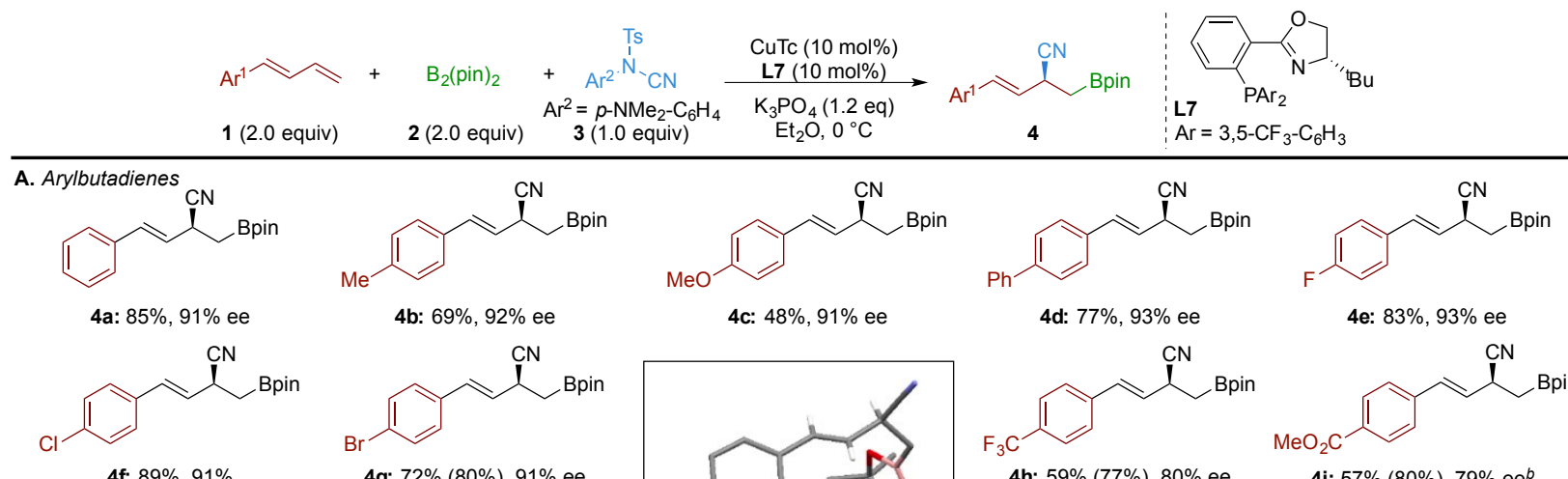

4b: $69 \%, 92 \%$ ee

4c: $48 \%, 91 \%$ ee
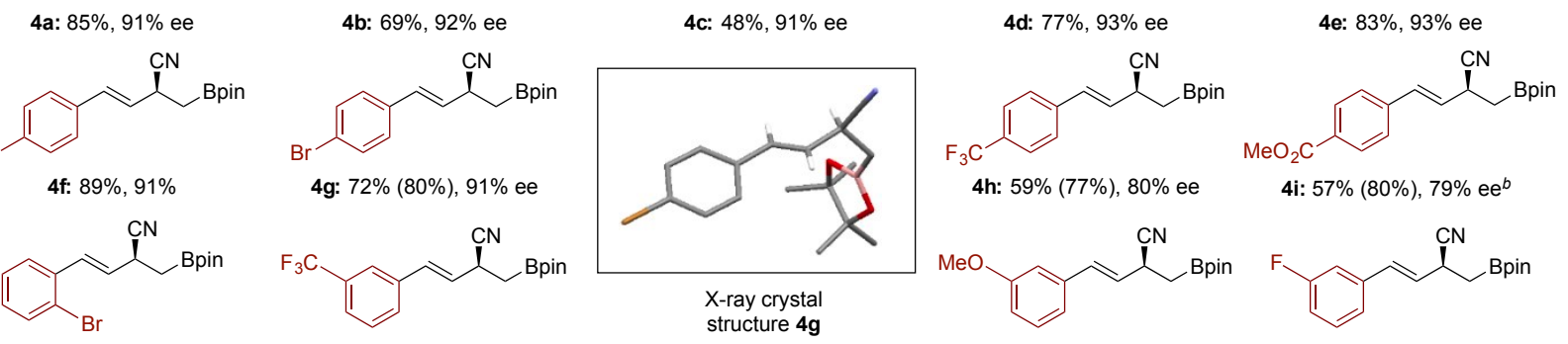

4k: $73 \%$ (82\%), $85 \%$ ee

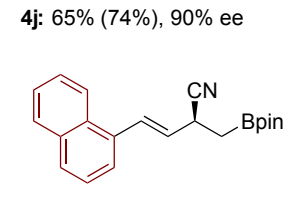

4n: $74 \%, 89 \%$ ee

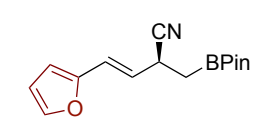

4r: $77 \%(88 \%), 90 \%$ ee

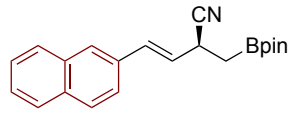

4o: $86 \%, 91 \%$ ee

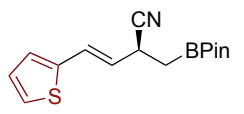

4s: $78 \%, 94 \%$ ee

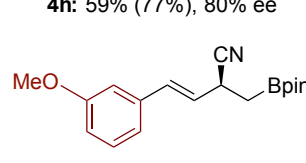

4l: $70 \%(93 \%), 88 \%$ ee

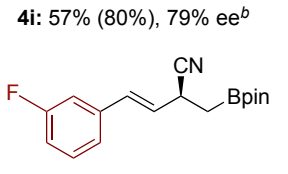

$4 \mathrm{~m}: 83 \%, 87 \% \mathrm{ee}^{b}$

B. Heteroarylbutadienes

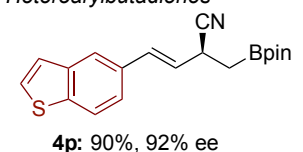<smiles>Cc1nc2cc(/C=C/[C@H](C#N)Cc3ccccc3)ccc2s1</smiles>

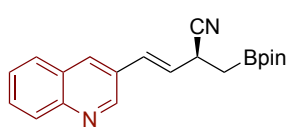

4t: $72 \%, 74 \%$ ee<smiles>Cn1cc(/C=C/[C@H](C#N)Cc2ccccc2)c(=O)[nH]c1=O</smiles>

4u: $49 \%,{ }^{c} 90 \%$ ee

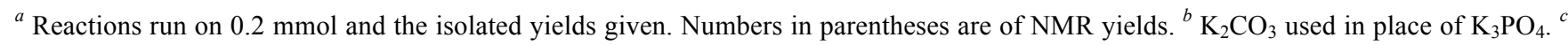
$\mathbf{4 u}: 5 \mathbf{u}=7: 1.5 \mathbf{u}$ is the minor 4,1 -addition product.

corresponding products in high NMR yield, however, a reduct ion in enantioselectivity was observed in these cases. The procedure was also applicable to a range of ortho- $(\mathbf{4 j})$ and metasubstituted (4k-4m) arylbutadienes, without significant detriment to the yield or enantioselectivity of the reaction. Finally, both 1- and 2-napthylbutadienes performed well under the reaction conditions $(\mathbf{4 n}, \mathbf{4 0})$. Overall, the application of our procedure to a range of substituted arylbutadienes gave the corresponding products with excellent regiocontrol, in good to excellent yields, and with high to excellent enantioselectivity (79-93\% ee).

We were also keen to test our procedure on heteroarylbutadienes as this type of substrate has yet to be applied in enantioselective borofunctionalizations (Scheme 3B). We were pleased to find that high yields and excellent enantioselectivities were obtained with benzothiophene $(4 \mathbf{p})$, benzothiazole (4q), furan (4r) and thiophene (4s) substituted 1,3-butadienes. Although the reaction with quinoline based diene $4 \mathbf{t}$ provided a good yield of the desired product, the enantioselectivity of the procedure was moderate. This reduction in enantiocontrol may be due to the substrate competing with the chiral ligand in binding to the copper catalyst. Although a uracil derived diene gave only moderate yield, the product was formed with excellent enantioselectivity (4u). Several multiply-substituted dienes were also tested (Scheme 4). We were pleased to observe that the reaction conditions were applicable to 1,2disubstituted dienes, however, both the yield and the enantioselectivity were lowered (4v, 4w, 4x).

Scheme 4. Scope of the copper-catalyzed enantioselective borocyanation of multiply-substituted dienes. ${ }^{a}$

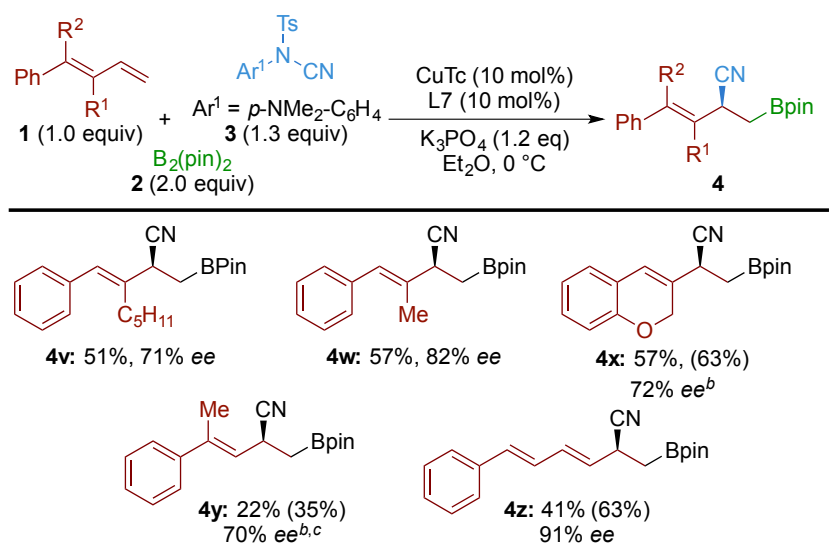

${ }^{a}$ Reactions run on $0.2 \mathrm{mmol}$ and the isolated yields given. Numbers in parentheses are of NMR yields. ${ }^{b} \mathrm{~K}_{2} \mathrm{CO}_{3}$ used in place of $\mathrm{K}_{3} \mathrm{PO}_{4} \cdot{ }^{c} \mathbf{4 y}: \mathbf{5 y}=13: 1.5 \mathrm{y}$ is the minor 4,1 -addition product. 
Scheme 5. A. Tentative stereochemical model; B. Proposed catalytic cycle for the enantioselective borocyanation of dienes; $C$. Investigating the reaction mechanism through hydroboration; $D$. The reactivity of trans- vs cis-dienes.

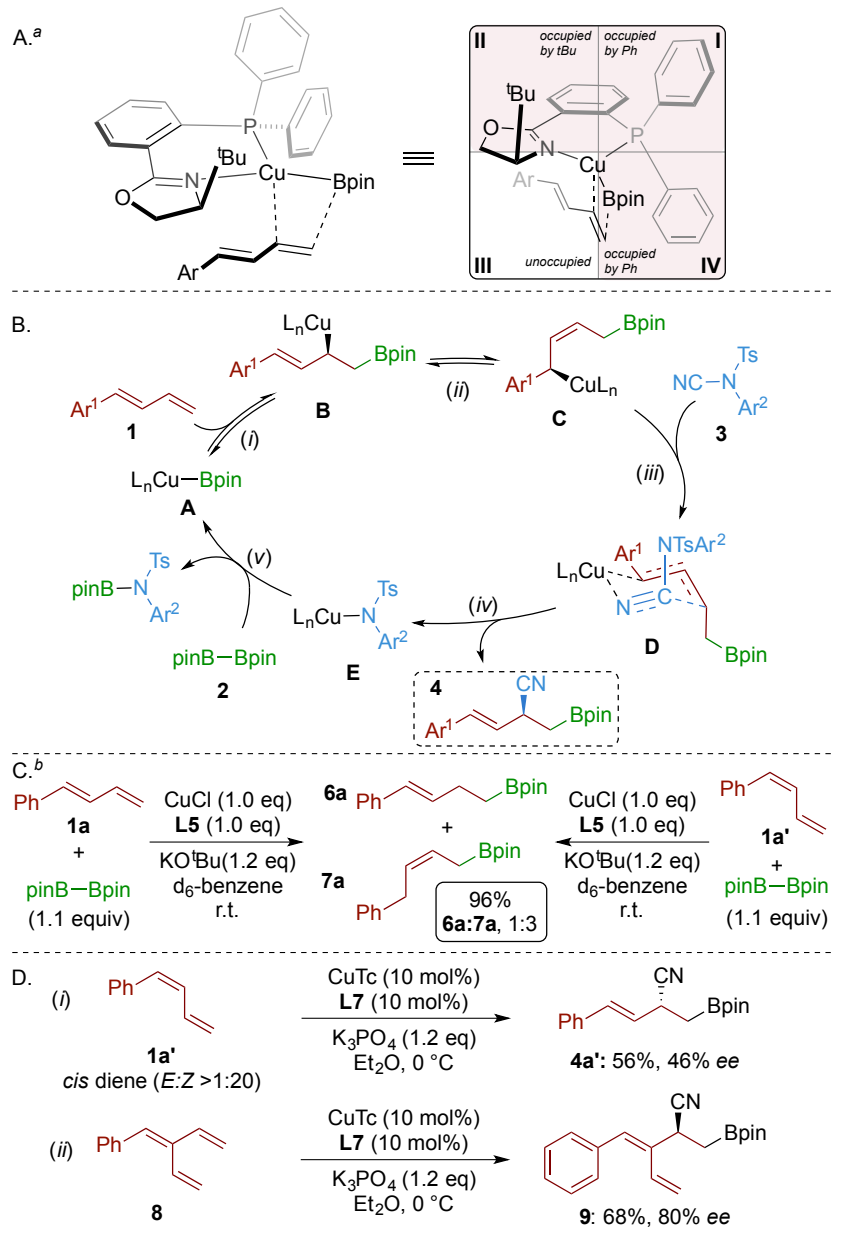

${ }^{a} \mathrm{CF}_{3}$ groups of ligand have been removed for clarity. ${ }^{b}$ Reactions run on $0.02 \mathrm{mmol}$.

A 1,1-disubstituted diene showed poor reactivity but gave product $4 \mathbf{y}$ with respectable enantiocontrol. The procedure could also be applied to the borocyanation of 1-phenyl-1,3,5hexatriene (1z) to give the diene product in good NMR yield and excellent enantioselectivity $(\mathbf{4 z})$. This result shows the potential of this methodology for the enantioselective dual functionalization of other polyunsaturated compounds.

A tentative stereochemical model and catalytic cycle for the transformation is presented in Scheme 5. The model invokes steric hindrance in quadrants I, II, and IV that would block the approach of the diene (Scheme 5A). This leaves quadrant III accessible for the diene $\mathbf{1}$ to approach the $\mathrm{Cu}-\mathrm{Bpin}$ bond leading to borocupration of the substrate to provide organocopper species B (Scheme 5A and 5B, i) ${ }^{23}$ Preliminary experiments by us (vide infra) and others have suggested that isomerization of $\mathbf{B}$ can lead to the thermodynamically more favorable (Z)allyl copper species $\mathbf{C}(i i))^{8 b, 9 q, 12,14,23,24}$ Steps consisting of a stereoselective insertion of the cyanating agent $\mathbf{3}$ (iii), followed by 1,2-elimination to release the copper amide species $\mathbf{E}$ would lead to the allyl nitrile product 4 (iv). On the basis of previous reports, we suggest that reaction of $\mathbf{C}$ with the cyanating agent $\mathbf{3}$ proceeds via the 6-membered transition structure D. ${ }^{7 c}$ Finally, the active copper catalyst $\mathbf{A}$ can be regenerated through sigma-bond metathesis of species $\mathbf{E}$ with $\mathrm{B}_{2} \operatorname{pin}_{2}{ }^{25}$ Attempts to isolate/observe the intermediate organocopper species $\mathbf{B}$ and $\mathbf{C}$ were unsuccessful. However, the corresponding products of hydroboration (6a and 7a) were observed when mixing the diene 1a with a stoichiometric amount of $\mathrm{CuCl}, \mathbf{L 5}$ and $\mathrm{B}_{2} \mathrm{pin}_{2}$ in the absence of the cyanating agent (Scheme $5 \mathrm{C}$ ) ${ }^{26,27}$ In line with the observations of Brown, ${ }^{14}$ we propose that the minor product $\mathbf{6 a}$ forms from protodemetallation of intermediate $\mathbf{B}$, and the major product $7 \mathbf{a}$ from protodemetallation of the $(Z)$-allyl intermediate $\mathbf{C}$. Interestingly, when using the cis-diene $\mathbf{1 a}^{\prime}$, the products $\mathbf{6 a}$ and $\mathbf{7 a}$ were also formed in the same ratios. These results suggest that, in the absence of an electrophile; 1) the dienes $\mathbf{1 a}$ and $\mathbf{1} \mathbf{a}^{\prime}$ converge to similar intermediates ${ }^{14}$ and 2) the isomerization of $\mathbf{B}$ and $\mathbf{C}$ is reversible. ${ }^{28}$ Due to the preferential formation of the (Z)hydroboration product, and in agreement with previous reports, ${ }^{8 b, 9 q, 12,14,23,24}$ we suggest that the cyanating agent 3 reacts with the (Z)-allyl species $\mathbf{C}$ to deliver the product with the observed stereochemistry (Scheme 5B, iii).

Interestingly, under the standard reaction conditions, the cisisomer of phenyl-1,3-butadiene (19') gave the $(E)$-alkene product $\mathbf{4 a}$ ' - the opposite enantiomer of product $4 \mathbf{a}$ that is formed using the trans-diene 1a (Scheme $5 \mathrm{D}, i$ ). This again highlights that the trans- (1a) and cis- (1a') isomers of phenyl-1,3butadiene converge to give a product with the same geometry about the alkene bond, though with opposite configuration at the $\mathrm{sp}^{3}$-carbon bearing the cyano group. ${ }^{29}$ Finally, the reaction of substrate $\mathbf{8}$, which shares features of both $\mathbf{1 a}$ (a trans-diene) and 1a' (a cis-diene) led to the product 9 (Scheme 5D, ii). The absolute configuration of this product suggests that borocupration occurs preferentially at the trans-alkenyl unit, thus implying that trans-dienes react faster than cis dienes in this process. ${ }^{30}$ Future studies will allow for a better understanding of the reactivity observed and allow closer comparison to related transition metal-catalyzed processes.

The products obtained from the enantioselective transformation of dienes contain boro-, cyano- and alkenyl functionalities, each of which can be readily manipulated (Scheme 6). For example, the boryl group can be easily transformed into alcohol $10(i)$. This prepares the molecule for an iodocyclization via reaction of the alkene with an iodonium reagent, to give multi-substituted tetrahydrofurans 11a and 11a' (ii). Alternatively, the alkene can be selectively reduced in the presence of the cyano group to give $\mathbf{1 2}$ (iii). The nitrile group is also susceptible to hydrolysis or reduction to give amide (13) or amine (14) containing products (iv, v). Importantly, no loss of enantiomeric purity was observed in these manipulations.

\section{Scheme 6. Manipulations of borocyanation products.}

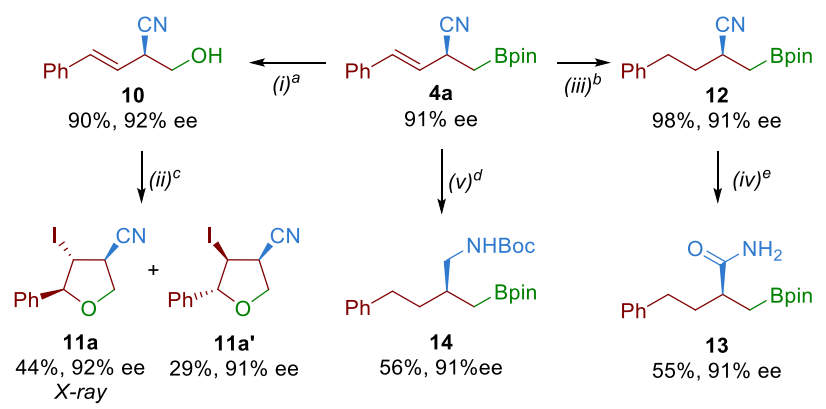

${ }^{a} \mathrm{H}_{2} \mathrm{O}_{2}, \mathrm{~K}_{2} \mathrm{CO}_{3}$ (2.0 eq), THF, $-20{ }^{\circ} \mathrm{C}, 16$ h. ${ }^{b} \mathrm{Pd} / \mathrm{C}(10 \mathrm{~mol} \%)$, $\mathrm{H}_{2}$, MeOH/EtOAc, rt, 16 h. ${ }^{c}$ Oxone $^{\circledR}$ (2.0 eq), KI (4.0 eq), $\mathrm{MeCN} / \mathrm{H}_{2} \mathrm{O}, \mathrm{rt}, 30$ min. ${ }^{d} \mathrm{NiCl}_{2}$ (1.5 eq), $\mathrm{NaBH}_{4}(10.0 \mathrm{eq}), \mathrm{Boc}_{2} \mathrm{O}$ 
(3.0 eq), $\mathrm{MeOH}, 0{ }^{\circ} \mathrm{C}, 2$ h. ${ }^{e} \mathrm{ZnBr}_{2}\left(1.0\right.$ eq) $, \mathrm{H}_{2} \mathrm{O} / \mathrm{i}-\mathrm{PrOH}, 90{ }^{\circ} \mathrm{C}$, $16 \mathrm{~h}$.

In conclusion, we have reported on the copper-catalyzed enantioselective borocyanation of unsaturated hydrocarbons: 1,3-Dienes undergo 4,3-borocyanation with excellent regioand enantiocontrol. Preliminary results show the potential application of this methodology to other unsaturated hydrocarbons, such as trienes, and we have demonstrated the high synthetic value of the products through various derivatisations. Further studies on the utility of this rare example of an enantioselective cyanation of an unsaturated feedstock are currently underway.

\section{ASSOCIATED CONTENT}

Supporting Information. Experimental procedures and characterization data are available free of charge via the Internet at http://pubs.acs.org.

\section{AUTHOR INFORMATION}

\section{Corresponding Author}

* Email: david.j.procter@manchester.ac.uk Website: www.proctergroupresearch.com Twitter: @GroupProcter

\section{Notes}

The authors declare no competing financial interests.

\section{ACKNOWLEDGMENT}

We thank the EPSRC (Established Career Fellowship to D.J.P.; EP/M005062/1), the Royal Society (Newton International Fellowship to T.J.) and the University of Manchester (Lectureships to A.P.P. and G.J.P.P). We also thank the X-ray Crystallography Service at the University of Manchester.

\section{REFERENCES}

(1) (a) Rajanbabu, T. V. Hydrocyanation of Alkenes and Alkynes. In Organic Reactions; John Wiley \& Sons, Inc.: Hoboken, NJ, USA, 2011; pp 1-74; b) RajanBabu, T. V. Hydrocyanation in Organic Synthesis. In Comprehensive Organic Synthesis II; Elsevier, 2014; Vol. 5 , pp 1772-1793.

(2) Tolman, C. A.; McKinney, R. J.; Seidel, W. C.; Druliner, J. D.; Stevens, W. R. Homogeneous Nickel-Catalyzed Olefin Hydrocyanation. In Advances in Catalysis; 1985; Vol. 33, pp 1-46.

(3) Tullo, A. H. "The chemical industry is bracing for a nylon 6,6 shortage," can be found under https://cen.acs.org/materials/polymers/chemical-industry-bracingnylon-66/96/i40, 2018.

(4) (a) Bäckvall, J.-E.; Andell, O. S. Stereochemistry and Mechanism of the Nickel-Catalysed Hydrocyanation of Conjugated Dienes. J. Chem. Soc., Chem. Commun. 1984, 260-261; (b) Tolman, C. A.; Seidel, W. C.; Druliner, J. D.; Domaille, P. J. Catalytic Hydrocyanation of Olefins by Nickel( 0 ) Phosphite Complexes - Effects of Lewis Acids. Organometallics 1984, 3, 33-38; (c) Tolman, C. A. Steric and Electronic Effects in Olefin Hydrocyanation at Du Pont: A Scientific and Industrial Success Story. J. Chem. Educ. 1986, 63, 199-201.

(5) (a) Hodgson, M.; Parker, D.; Taylor, R. J.; Ferguson, G. Synthetic and Mechanistic Aspects of Palladium-Catalyzed Asymmetric Hydrocyanation of Alkenes. Crystal Structure and Reactions of $\left(\eta^{2}\right.$ Ethene)(diop)Palladium. Organometallics 1988, 7, 1761-1766; (b) Casalnuovo, A. L.; RajanBabu, T. V.; Ayers, T. A.; Warren, T. H. Ligand Electronic Effects in Asymmetric Catalysis: Enhanced Enantioselectivity in the Asymmetric Hydrocyanation of Vinylarenes. $J$. Am. Chem. Soc. 1994, 116, 9869-9882; (c) Horiuchi, T.; Shirakawa, E.; Nozaki, K.; Takaya, H. (R,S)-BINAPHOS-Ni(0) and -Pd(0) Com- plexes: Characterization and Use for Asymmetric Hydrocyanation of Norbornene. Tetrahedron: Asymmetry 1997, 8, 57-63; (d) Goertz, W.; Kamer, P. C. J.; van Leeuwen, P. W. N. M.; Vogt, D. Asymmetric Nickel-Catalyzed Hydrocyanation of Vinylarenes by Applying Homochiral Xantphos Ligands. Chem. Eur. J. 2001, 7, 1614-1618; (e) Wilting, J.; Janssen, M.; Müller, C.; Vogt, D. The Enantioselective Step in the Nickel-Catalyzed Hydrocyanation of 1,3-Cyclohexadiene. J. Am. Chem. Soc. 2006, 128, 11374-11375; (f) Saha, B.; RajanBabu, T. V. Nickel(0)-Catalyzed Asymmetric Hydrocyanation of 1,3Dienes. Org. Lett. 2006, 8, 4657-4659; (g) Falk, A.; Göderz, A.-L.; Schmalz, H.-G. Enantioselective Nickel-Catalyzed Hydrocyanation of Vinylarenes Using Chiral Phosphine-Phosphite Ligands and TMS-CN as a Source of HCN. Angew. Chem. Int. Ed. 2013, 52, 1576-1580; (h) Falk, A.; Cavalieri, A.; Nichol, G. S.; Vogt, D.; Schmalz, H.-G. Enantioselective Nickel-Catalyzed Hydrocyanation Using Chiral Phosphine-Phosphite Ligands: Recent Improvements and Insights. $A d v$. Synth. Catal. 2015, 357, 3317-3320. For a recent review on this subject, see: (i) Kurono, N.; Ohkuma, T. Catalytic Asymmetric Cyanation Reactions. ACS Catal. 2016, 6, 989-1023.

(6) For reviews on this subject see: (a) Shimizu, Y.; Kanai, M. Recent Progress in Copper-Catalyzed Difunctionalization of Unactivated Carboncarbon Multiple Bonds. Tetrahedron Lett. 2014, 55, 3727 3737; (b) Semba, K.; Fujihara, T.; Terao, J.; Tsuji, Y. CopperCatalyzed Borylative Transformations of Non-Polar Carbon-carbon Unsaturated Compounds Employing Borylcopper as an Active Catalyst Species. Tetrahedron 2015, 71, 2183-2197; (c) Sorádová, Z.; Šebesta, R. Enantioselective Cu-Catalyzed Functionalizations of Unactivated Alkenes. ChemCatChem 2016, 8, 2581-2588; (d) Xiong, Y.; Sun, Y.; Zhang, G. Recent Advances on Catalytic Asymmetric Difunctionalization of 1,3-Dienes. Tetrahedron Lett. 2018, 59, 347-355.

(7) For related copper-catalyzed racemic reductive cyanations of $\mathrm{C}=\mathrm{C}$ bonds see: (a) Yang, Y.; Buchwald, S. L. Copper-Catalyzed Regioselective Ortho $\mathrm{C}-\mathrm{H}$ Cyanation of Vinylarenes. Angew. Chem. Int. Ed. 2014, 53, 8677-8681; (b) Zhao, W.; Montgomery, J. Functionalization of Styrenes by Copper-Catalyzed Borylation/ ortho Cyanation and Silver-Catalyzed Annulation Processes. Angew. Chem. Int. Ed. 2015, 54, 12683-12686; (c) Yang, Y.; Liu, P. Mechanism and Origins of Selectivities in the Copper-Catalyzed DearomatizationInduced ortho $\mathrm{C}-\mathrm{H}$ Cyanation of Vinylarenes. ACS Catal. 2015, 5, 2944-2951; (d) Yang, Y. Regio- and Stereospecific 1,3-Allyl Group Transfer Triggered by a Copper-Catalyzed Borylation/orthoCyanation Cascade. Angew. Chem. Int. Ed. 2016, 55, 345-349; (e) Zhao, W.; Montgomery, J. Cascade Copper-Catalyzed 1,2,3Trifunctionalization of Terminal Allenes. J. Am. Chem. Soc. 2016, 138, 9763-9766; (f) He, S.-J.; Wang, B.; Lu, X.; Gong, T.-J.; Yang, Y.-N.; Wang, X.-X.; Wang, Y.; Xiao, B.; Fu, Y. Copper-Catalyzed Reagent-Controlled Regioselective Cyanoborylation of Vinylarenes. Org. Lett. 2018, 20, 5208-5212.

(8) For racemic copper-catalyzed borofunctionalisations of dienes see: (a) Huang, Y.; Smith, K. B.; Brown, M. K. Copper-Catalyzed Borylacylation of Activated Alkenes with Acid Chlorides. Angew. Chem. Int. Ed. 2017, 56, 13314-13318; (b) Smith, K. B.; Brown, M. K. Regioselective Arylboration of Isoprene and Its Derivatives by $\mathrm{Pd} / \mathrm{Cu}$ Cooperative Catalysis. J. Am. Chem. Soc. 2017, 139, 77217724; (c) Jia, T.; He, Q.; Ruscoe, R. E.; Pulis, A. P.; Procter, D. J. Regiodivergent Copper Catalyzed Borocyanation of 1,3-Dienes. Angew. Chem. Int. Ed. 2018, 57, 11305-11309; (d) Wen, L.; Zhang, H.; Wang, J.; Meng, F. Cu-catalyzed regioselective borylcyanation of 1,3dienes. Chem. Commun. 2018, 54, 12832-12835; (e) Li, D.; Park, Y.; Yun, J. Org. Lett. 2018, 20, 7526-7529; (f) Feng J.-J.; Oestreich, M. Tertiary $\alpha$ Silyl Alcohols by Diastereoselective Coupling of 1,3 Dienes and Acylsilanes Initiated by Enantioselective Copper Catalyzed Borylation. Angew. Chem. Int. Ed. 2019, 10.1002/anie.201903174.

(9) For related $\mathrm{Cu}$-catalyzed functionalizations of 1,3-dienes see, for hydrogenation: (a) Semba, K.; Fujihara, T.; Xu, T.; Terao, J.; Tsuji, Y. Copper-Catalyzed Highly Selective Semihydrogenation of Non-Polar Carbon-Carbon Multiple Bonds using a Silane and an Alcohol. Adv. Synth. Catal. 2012, 354, 1542-1550; for hydroboration: 
(b) Sasaki, Y.; Zhong, C.; Sawamura, M.; Ito, H. Copper(I)-Catalyzed Asymmetric Monoborylation of 1,3-Dienes: Synthesis of Enantioenriched Cyclic Homoallyl- and Allylboronates. J. Am. Chem. Soc. 2010, 132, 1226-1227; (c) Semba, K.; Shinomiya, M.; Fujihara, T.; Terao, J.; Tsuji, Y. Highly Selective Copper-Catalyzed Hydroboration of Allenes and 1,3-Dienes. Chem. Eur. J. 2013, 19, 7125-7132; (d) Kitanosono, T.; Xu, P.; Kobayashi, S. Heterogeneous and homogeneous chiral $\mathrm{Cu}(\mathrm{II})$ catalysis in water: Enantioselective boron conjugate additions to dienones and dienoesters. Chem. Commun. 2013, 49 , 8184-8186; (e) Luo, Y.; Roy, I. D.; Madec, A. G. E.; Lam, H. W. Enantioselective synthesis of allylboronates and allylic alcohols by copper-catalyzed 1,6-boration. Angew. Chem. Int. Ed. 2014, 53, 4186-4190; (f) Jarava-Barrera, C.; Parra, A.; López, A.; Cruz-Acosta, F.; Collado-Sanz, D.; Cárdenas, D. J.; Tortosa, M. Copper-Catalyzed Borylative Aromatization of $\mathrm{p}$-Quinone Methides: Enantioselective Synthesis of Dibenzylic Boronates. ACS Catal. 2016, 6, 442-446; (g) Kubota, K.; Watanabe, Y.; Hayama, K.; Ito, H. Enantioselective Synthesis of Chiral Piperidines via the Stepwise Dearomatization/Borylation of Pyridines. J. Am. Chem. Soc. 2016, 138, 43384341; (h) Liu, Y.; Fiorito, D.; Mazet, C. Copper-catalyzed enantioselective 1,2-borylation of 1,3-dienes. Chem. Sci. 2018, 9, 5284-5288; (i) Luo, Y.; Wales, S. M.; Korkis, S. E.; Roy, I. D.; Lewis, W.; Lam, H. W. Switchable Synthesis of Z -Homoallylic Boronates and E Allylic Boronates by Enantioselective Copper-Catalyzed 1,6Boration. Chem. Eur. J., 2018, 24, 8315-8319; (j) Lee, H.; Yun, J. Copper(I)-Catalyzed Enantioselective 1,6-Borylation of $\alpha, \beta, \gamma, \delta$ Unsaturated Phosphonates. Org. Lett. 2018, 20, 7961-7964; (k) Gao, S.; Wang, M.; Chen, M. Syntheses of Unsymmetrical 1,4Bifunctional Allylboron Reagents via Cu-catalyzed Highly Regioand Stereoselective 1,4-Protoboration of Dienylboronates and Analysis of the Origin of Chemoselective Aldehyde syn(Hydroxymethyl)allylation. Org. Lett. 2018, 20, 7921-7925; for hydrofunctionalisation: (l) Iwasaki, T.; Shimizu, R.; Imanishi, R.; Kuniyasu, H.; Kambe, N. Copper-Catalyzed Regioselective Hydroalkylation of 1,3-Dienes with Alkyl Fluorides and Grignard Reagents. Angew. Chem. Int. Ed. 2015, 54, 9347-9350; (m) Yang, Y.; Perry, I. B.; Lu, G.; Liu, P.; Buchwald, S. L. Copper-catalyzed asymmetric addition of olefin-derived nucleophiles to ketones. Science 2016, 353, 144-150; (n) Gui, Y.-Y.; Hu, N.; Chen, X.-W.; Liao, L.; Ju, T.; Ye, J.-H.; Zhang, Z.; Li, J.; Yu, D.-G. Highly Regio- and Enantioselective Copper-Catalyzed Reductive Hydroxymethylation of Styrenes and 1,3-Dienes with $\mathrm{CO}_{2}$. J. Am. Chem. Soc. 2017, 139, 17011-17014; (o) Iwasaki, T.; Okamoto, K.; Kuniyasu, H.; Kambe, N. Cu-catalyzed Reductive Coupling of Perfluoroarenes with 1,3-Dienes. Chem. Lett. 2017, 46, 1504-1507; (p) Li, M.; Wang, J.; Meng, F. Cu-Catalyzed Enantioselective Reductive Coupling of 1,3-Dienes and Aldimines. Org. Lett. 2018, 20, 7288-7292; (q) Li, C.; Liu, R. Y.; Jesikiewicz, L. T.; Yang, Y.; Liu, P.; Buchwald, S. L. CuH-Catalyzed Enantioselective Ketone Allylation with 1,3-Dienes: Scope, Mechanism, and Applications. J. Am. Chem. Soc. 2019, 141, 5062-5070.

(10) Hemming, D.; Fritzemeier, R.; Westcott, S. A.; Santos, W. L.; Steel, P. G. Copper-boryl mediated organic synthesis. Chem. Soc. Rev. 2018, 47, 7477-7494.

(11) Li, X.; Meng, F.; Torker, S.; Shi, Y.; Hoveyda, A. H. Catalytic Enantioselective Conjugate Additions of (pin)B-Substituted Allylcopper Compounds Generated in situ from Butadiene or Isoprene. Angew. Chem. Int. Ed. 2016, 55, 9997-10002.

(12) Jiang, L.; Cao, P.; Wang, M.; Chen, B.; Wang, B.; Liao, J. Highly Diastereo- and Enantioselective Cu-Catalyzed Borylative Coupling of 1,3-Dienes and Aldimines. Angew. Chem. Int. Ed. 2016, $55,13854-13858$.

(13) Smith, K. B.; Huang, Y.; Brown, M. K. Copper-Catalyzed Heteroarylboration of 1,3-Dienes with 3-Bromopyridines: A cine Substitution. Angew. Chem. Int. Ed. 2018, 57, 6146-6149.

(14) Sardini, S. R.; Brown, M. K. Catalyst Controlled Regiodivergent Arylboration of Dienes. J. Am. Chem. Soc. 2017, 139, $9823-$ 9826.

(15) (a) Pace, V.; Rae, J. P.; Harb, H. Y.; Procter, D. J. NHC-Cu(I) catalysed asymmetric conjugate silyl transfer to unsaturated lactones: application in kinetic resolution. Chem. Commun. 2013, 49, 5150; (b) Rae, J.; Hu, Y. C.; Procter, D. J. Cu(I)-NHC-Catalyzed Silylation of Allenes: Diastereoselective Three-Component Coupling with Aldehydes Chem. Eur. J. 2014, 20, 13143-13145; (c) Pace, V.; Rae, J. P.; Procter, D. J. $\mathrm{Cu}(\mathrm{I})-\mathrm{NHC}$ Catalyzed Asymmetric Silyl Transfer to Unsaturated Lactams and Amides. Org. Lett. 2014, 16, 476-479; (d) Rae, J.; Yeung, K.; McDouall, J. J. W.; Procter, D. J. CopperCatalyzed Borylative Cross-Coupling of Allenes and Imines: Selective Three-Component Assembly of Branched Homoallyl Amines. Angew. Chem. Int. Ed. 2016, 55, 1102-1107; (e) Yeung, K.; Ruscoe, R. E.; Rae, J.; Pulis, A. P.; Procter, D. J. Enantioselective Generation of Adjacent Stereocenters in a Copper-Catalyzed Three-Component Coupling of Imines, Allenes, and Diboranes. Angew. Chem. Int. Ed. 2016, 55, 11912-11916; (f) Pulis, A. P.; Yeung, K.; Procter, D. J. Enantioselective copper catalysed, direct functionalisation of allenes via allyl copper intermediates. Chem. Sci. 2017, 8, 5240-5247; (g) Yeung, K.; Talbot, F. J. T.; Howell, G. P.; Pulis, A. P.; Procter, D. J. Copper-Catalyzed Borylative Multicomponent Synthesis of Quaternary $\alpha$-Amino Esters. ACS Catal. 2019, 9, 1655-1661.

(16) For selected examples of the Cu-catalyzed enantioselective cyanation of other substrates, see: (a) Zhang, W.; Wang, F.; McCan, S. D.; Wang, D.; Chen, P.; Stahl, S. S.; Liu, G. Enantioselective cyanation of benzylic $\mathrm{C}-\mathrm{H}$ bonds via copper-catalyzed radical relay. Science 2016, 353, 1014-1018. (b) Wang, F.; Wang, D.; Wan, X. Wu, L.; Chen, P.; Liu, G. Enantioselective Copper-Catalyzed Intermolecular Cyanotrifluoromethylation of Alkenes via Radical Process. J. Am. Chem. Soc. 2016, 138, 15547-15550. (c) Wang, D.; Zhu, N.; Chen, P.; Lin, Z.; Liu, G. Enantioselective Decarboxylative Cyanation Employing Cooperative Photoredox Catalysis and Copper Catalysis. J. Am. Chem. Soc. 2017, 139, 15632-15635. (d) Sha, W.; Deng, L.; Ni, S.; Mei, H.; Han, J.; Pan, Y. Merging Photoredox and Copper Catalysis: Enantioselective Radical Cyanoalkylation of Styrenes. ACS Catal. 2018, 8, 7489-7494. (e) Yang, S.; Wang, L.; Zhang, H.; Liu, C.; Zhang, L.; Wang, X.; Zhang, G.; Li, Y.; Zhang Q. CopperCatalyzed Asymmetric Aminocyanation of Arylcyclopropanes for Synthesis of $\gamma$-Amino Nitriles. ACS Catal. 2019, 9, 716-721. (f) Lu, F.-D.; Liu, D.; Zhu, L.; Lu, L.-Q.; Yang, Q.; Zhou, Q.-Q.; Wei, Y.; Lan, Y.; Xiao, W.-J. Asymmetric Propargylic Radical Cyanation Enabled by Dual Organophotoredox and Copper Catalysis. J. Am. Chem. Soc. 2019, 141, 6167-6172. (g) Guo, Q.; Wang, M.; Peng, Q.; Huo, Y.; Liu, Q.; Wang, R.; Xu, Z. Dual-Functional Chiral CuCatalyst-Induced Photoredox Asymmetric Cyanofluoroalkylation of Alkenes. ACS Catal. 2019, 9, 4470-4476.

(17) For recent reviews on the use of cyanamides in organic synthesis see: (a) Prabhath, M.; Williams, L.; Bhat, S.; Sharma, P. Recent Advances in Cyanamide Chemistry: Synthesis and Applications. Molecules 2017, 22, 615; (b) Cui, J.; Song, J.; Liu, Q.; Liu, H.; Dong, Y. Transition Metal Catalyzed Cyanation by Using an Electrophilic Cyanating Agent, $\mathrm{N}$ Cyano $\mathrm{N}$ phenyl $\mathrm{p}$ toluenesulfonamide (NCTS). Chem. Asian J. 2018, 13, 482-495; (c) Chaitanya, M.; Anbarasan, P. Recent developments and applications of cyanamides in electrophilic cyanation. Org. Biomol. Chem. 2018, 16, 7084-7103.

(18) See the SI for further details of the optimisation and the inclusion of some other unsuccessful substrates.

(19) (a) Williams, J. M. J. The Ups and Downs of Allylpalladium Complexes in Catalysis. Synlett 1996, 1996, 705-710; (b) Pfaltz, A. Design of Chiral Ligands for Asymmetric Catalysis: from C2Symmetric Semicorrins and Bisoxazolines to Non-Symmetric Phosphinooxazolines. Acta Chem. Scand. 1996, 50, 189-194; (c) Helmchen, G.; Kudis, S.; Sennhenn, P.; Steinhagen, H. Enantioselective catalysis with complexes of asymmetric P,N-chelate ligands. Pure Appl. Chem. 1997, 69, 513-518; (d) Helmchen, G.; Pfaltz, A. PhosphinooxazolinesA New Class of Versatile, Modular P,N-Ligands for Asymmetric Catalysis. Acc. Chem. Res. 2000, 33, 336-345.

(20) Although the use of PHOX ligands has been investigated, they have not been used as the ligand of choice in any previous reactions involving borocupration of alkenes/alkynes: (a) Liu, P.; Fukui, Y.; Tian, P.; He, Z.-T.; Sun, C.-Y.; Wu, N.-Y.; Lin, G.-Q. Cu-Catalyzed Asymmetric Borylative Cyclization of Cyclohexadienone-Containing 
1,6-Enynes. J. Am. Chem. Soc. 2013, 135, 11700-11703; (b) Gan, X.C.; Yin, L. Asymmetric Borylative Propargylation of Ketones Catalyzed by a Copper(I) Complex. Org. Lett. 2019, 21, 931-936.

(21) The absolute stereochemistry of the product was determined by $\mathrm{X}$-ray crystallographic analysis of product $\mathbf{4 g}$.

(22) Lin, S.; Lin, Z. DFT Studies on the Mechanism of CopperCatalyzed Boracarboxylation of Alkene with $\mathrm{CO} 2$ and Diboron. Organometallics 2019, 38, 240-247.

(23) Previous studies suggest that the 4,3-addition of the $\mathrm{L}_{n} \mathrm{Cu}-$ Bpin complex to the diene via a 4-membered transition state would be favoured over 4,1-addition via a 6-membered transition state, see ref $9 \mathrm{q}$ and Li, X.; Wu, H.; Wu, Z.; Huang, G. Mechanism and Origins of Regioselectivity of Copper-Catalyzed Borocyanation of 2-ArylSubstituted 1,3-Dienes: A Computational Study. J. Org. Chem. 2019 , $84,5514-5523$.

(24) Janesko, B. G.; Villegas, H. Attractive Nonbonded Interactions Help Stabilize the Z Form of Alkenyl Anions. J. Org. Chem. 2018, $83,8208-8213$

(25) The active $\mathrm{L}_{n} \mathrm{Cu}$-Bpin catalytic species is often proposed to form through reaction of the $\mathrm{Cu}$ salt, a base and $\mathrm{B}_{2} \mathrm{pin}_{2}$, see ref 10 .

(26) $\mathbf{C u C l}, \mathrm{KO}^{t} \mathrm{Bu}$ and $\mathbf{~} \mathbf{5}$ were used in the stoichiometric reaction in place of CuTc, $\mathrm{K}_{3} \mathrm{PO}_{4} / \mathrm{K}_{2} \mathrm{CO}_{3}$ and $\mathbf{L 7}$. During optimisation, it was observed that the use of $\mathrm{CuCl}, \mathrm{KO}^{t} \mathrm{Bu}$ and $\mathbf{L 5}$ led to similar yields and regiocontrol, but lower enantiocontrol, when compared to use of the optimised conditions.
(27) A proton source (e.g. $\mathrm{MeOH}$ ) was not required to obtain the hydroboration products $\mathbf{6 a / 7} \mathbf{a}$. It is likely that adventitious water is responsible for the protonation of the unstable phosphine ligated-Cuallyl species (B and C). Previous studies on copper catalysed hydroboration have also observed hydroboration products without the addition of a proton source. See ref 7e and; Lee, Y.; Hoveyda, A. H. Efficient Boron-Copper Additions to Aryl-Substituted Alkenes Promoted by $\mathrm{NHC}-$ Based Catalysts. Enantioselective $\mathrm{Cu}-\mathrm{Catalyzed} \mathrm{Hydrobora-}$ tion Reactions. J. Am. Chem. Soc. 2009, 131, 3160-3161.

(28) Hydroboration product $\mathbf{6} \mathbf{a}$ can only form from $\mathbf{1} \mathbf{a}^{\mathbf{6}}$ if isomerisation can occur between organocopper species $\mathbf{B}$ and $\mathbf{C}$.

(29) Dong and co-workers also observed that cis- and trans-dienes converge to give an $(E)$-product during the study of a palladiumcatalyzed enantioselective hydrofunctionalisation of dienes. However, the same enantiomer of product was obtained, in high enantiopurity, regardless of whether the cis- or trans-diene was used. It was suggested that reversible hydro-palladation/isomerization (c.f. Scheme $5 \mathrm{~b}$, i/ii) was occuring faster than reaction with the electrophile (c.f. Scheme $5 \mathrm{~b}, \mathrm{iii}$ ). In our case, we propose that reversible borocupration/isomerization is slower than reaction with the electrophile. Nie, S.Z.; Davison, R. T.; Dong, V. M. Enantioselective Coupling of Dienes and Phosphine Oxides. J. Am. Chem. Soc. 2018, 140, 16450-16454.

(30) If the cis-alkenyl unit were to react, we would expect to obtain the opposite enantiomer of the product. The absolute configuration of 9 was determined by X-ray crystallographic analysis of a derivative. See the Supporting Information. 
For Table of Contents only

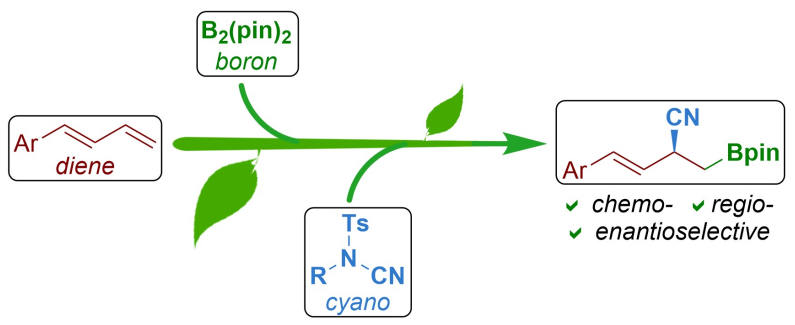

